\title{
COMMENTARY
}

\section{Ethical Decision-Making in the Pharmacists' Patient Care Process}

\author{
Brian L. Erstad, PharmD \\ University of Arizona, College of Pharmacy, Tucson, Arizona
}

Corresponding Author: Brian L. Erstad, University of Arizona, College of Pharmacy, 1295 N. Martin Ave., Tucson, AZ 85721. Tel: 520-626-4289. Email: erstad@ pharmacy.arizona.edu

Submitted March 24, 2021; accepted April 28, 2021; ePublished May 2021

\begin{abstract}
The intent of the Pharmacists' Patient Care Process (PPCP) is to provide a comprehensive approach to team-based, comprehensive patient-centered care. Consideration of potential ethical issues is a necessary component of comprehensive care provision and is a requirement of accreditation standards, but there is no specific mention of ethics in any of the phases of the PPCP. A more explicit incorporation of ethical decision-making into the PPCP should help faculty involved in teaching ethics and students who need to incorporate ethical considerations into the PPCP in order to provide optimal patient care. The aims of this commentary are to provide faculty with a foundational introduction to ethics and an explicit approach for incorporating ethical decision-making into the PPCP.

Keywords: ethical issues, clinical, academic
\end{abstract}

\section{INTRODUCTION}

Beginning in January of 2012, a workgroup promulgated under the auspices of the Joint Commission of Pharmacy Practitioners (JCPP) began work on a patient care process in order to "stimulate consistency, predictability, and measurability in pharmacists' service delivery." The resulting Pharmacists' Patient Care Process (PPCP) document approved in May of 2014 had the support of 13 national pharmacy organizations. Subsequently, the PPCP was incorporated into the accreditation standards of the Accreditation Council for Pharmacy Education (ACPE). ${ }^{2}$ One of the stated goals of the process is to provide a comprehensive approach to team-based, patient-centered care. Although consideration of potential ethical issues is a necessary component of comprehensive care provision and is a requirement of ACPE accreditation standards, ${ }^{2}$ there is no specific mention of ethics in any of the phases of the PPCP other than the reference to patient preferences and beliefs in the data collection phase of the process. Additionally, there is little consistency in pharmacy student education in ethics beyond recitation of codes and pledges supported by major pharmacy organizations and associations. ${ }^{3-5}$ While the latter documents contain statements concerning general ethical principles, they have only an indirect association with the five steps of the PPCP. A more explicit approach for incorporating ethical decision-making into the PPCP should help faculty involved in teaching ethics, as well as students who need to incorporate ethical considerations into their patient care plans. The aims of this commentary are to provide faculty with a foundational introduction to ethics and an explicit approach for incorporating ethical decision-making into the PPCP. There is no intent to replace, revise or complicate the simple and straightforward PPCP document released by the JCPP, but rather to use the document as a template for delineating important ethical considerations when providing patient care. Ethics Terminology

An overview of ethics terminology is useful for understanding ethical decision-making as part of the PPCP. There are three divisions or categories of traditional ethics: meta-ethics (study of morality), normative ethics (principles to determine whether action is right or good), and applied ethics (application to specific situations). ${ }^{6-9}$ For incorporation into the PPCP and for application to specific patients, the important concepts pertain to normative and applied ethics. A subcategorization of normative ethics has three divisions of consequentialist, non-consequentialist, and agent-centered theories. Within each of these three broad divisions, there is further subcategorization into approaches useful for ethical decision-making (Figure 1). ${ }^{6,9}$ Advances in fields of social-psychological research demonstrate that while general concepts of morality are universal, there are cross-national, sociocultural differences in the importance of virtues over time. ${ }^{10}$ Additionally, it is important to realize that the various approaches to ethical decision-making are not mutually exclusive and often present as conflicting options. Therefore, when faced with a specific situation in practice, the pharmacist should contemplate all approaches in the decision-making process. Deliberate contemplation is key, since studies in moral psychology demonstrate that when humans make moral judgments, they have an immediate emotional response referred to as moral intuition that does not consider the evidence pertaining to a specific situation. ${ }^{11}$ This is contrasted with moral reasoning that involves prolonged and considered contemplation necessary to make a well-informed 
decision. Moral reasoning is not a dichotomous process in which either you possess it or not; rather, it can be refined through ongoing practice and through mentoring by morally exemplary individuals.

There are attempts to distill the previous approaches to ethical decision-making into a more relevant discussion aimed at healthcare professionals. Two textbooks serve as particularly useful references for pharmacists. The first is a text that discusses ethical decision-making, particularly with respect to the APhA Code of Ethics. The authors list fair dealing and equity, patient-centered care, and faithfulness as virtues common to practicing pharmacists. ${ }^{7}$ A second useful text for ethical decision-making titled, "Principles of Biomedical Ethics" tends to be somewhat more physician-centric, but the discussion is appropriate for all healthcare professionals involved with clinical practice and human subjects research. ${ }^{8}$ In this text, the discussion begins with caring as the central or fundamental virtue said to originate in feminist writings. As discussed by the authors, caring is not just a function of emotional sensitivity, but also involves cognitive aspects related to understanding a patient's perspective and feelings. The authors then list the focal virtues of compassion (a precondition for caring), conscientiousness, discernment, integrity, and trustworthiness. Other virtues especially relevant to healthcare professionals include benevolence, fidelity, justice, nonmalevolence, respectfulness, and truthfulness. Of particular usefulness in text is the framework of norms proposed as starting point for decision-making in biomedical ethics. The framework based on a term called principlism, entails four clusters of general principles that are different but may overlap the rules and rights approaches discussed earlier. The clusters are respect for autonomy (right to hold views and make decisions based on those views), nonmaleficence (avoiding action causing harm), beneficence (requiring action to maximize benefit and avoid harm), and justice (fairness). These clusters of moral principles are professional obligations and serve as vital norms in a common morality-based framework that is a starting point for biomedical ethics. These clusters have similarities and overlap with the three basic principles (ie, respect for persons, beneficence, and justice) serving as the foundation of the Belmont Report, which provides ethical principles and guidelines for the conduct of human subjects research. ${ }^{12}$

\section{DISCUSSION}

\section{Ethical Decision-Making in the Patient Care Process}

The general steps for the process of ethical decision-making as recommended by experts in the field have much in common with the steps of the PPCP. Two different resources pertaining to ethics recommend the same following five steps: recognize the ethical issue, collect information, assess alternatives, make a decision and consider it, and implement and reflect on the outcome. ${ }^{6,9}$ The only substantial difference is that one of the sources has a recommendation to consider all parties involved after recognizing an ethical issue. ${ }^{6}$ These five recommended steps are almost identical to those of the PPCP: collect, assess, plan, implement, and follow-up: monitor and evaluate. The remainder of this paper describes a version of the PPCP that highlights the importance of ethical issues in each of these five steps (Table 1). It is not the intent of this version to denigrate or replace the important components of the original process, but rather to help the user explicitly consider ethics as part of the decision-making process.

Collect

During the data collection phase, one of the important points is to determine potential surrogate decision-makers for the patient, since the ethical principle of autonomy (right to make decisions about care regardless of clinician's recommendations) only applies to mentally competent patients. Nevertheless, the ethical principle of respect for persons means that while individuals are entitled to care as autonomous agents, persons with diminished autonomy are still entitled to protections. Data collection related to a patient's preferences and beliefs should include potential religious beliefs that might have implications for therapy. Collection and consideration of all relevant patient-specific data by the care team is necessary in order to help the patient or patient's surrogate make informed decisions. Historically, the focus of ethical decision-making was relatively paternalistic with primary concerns of nonmaleficence and beneficence, but now there is increased recognition of the importance of patient autonomy in the decision-making process. However, patient's desires or demands do not always come to fruition, since there may be other ethical, legal, or policy considerations that the care team must take into account when developing a patient care plan.

Assess

One consideration during the assessment phase relates to perspectives in addition to those of the patient that might have ethical implications. In settings of team-based interprofessional care, the perspective of other caregivers is important. Similarly, the pharmacist and other caregivers need to take into account institutional and societal perspectives. What patients might perceive to be in their best interests may conflict with other legitimate considerations such as medications available on an institutional formulary or evaluations of cost-effectiveness that have institutional and societal implications. While respect for patient autonomy dictates that informed decisions by patients are a priority, other perspectives are deserving of inclusion in the decision-making process. Since application of each of the theories may result in the same or 
different conclusion when applying to a specific patient situation, the clinician needs to contemplate how to balance all theories and norms in the decision-making process.

Plan

Since ethical principles may conflict with each other, the decision-making process is not always straightforward when ethical issues are involved. Furthermore, there may be a need for differential applications of ethical principles depending on patient-specific factors such as age, race, gender, and socioeconomic status that may predispose patients to worse outcomes. For example, concerning the principle of justice, treating patients the same or equally is important unless they differ in ways relevant to a specific situation (e.g. access to a life-saving medication even if a patient cannot pay for it). Similarly, while the principle of beneficence that maximizes patient benefit might seem straightforward, there is increasing recognition of paternalistic decision-making on the part of caregivers that does not fully respect autonomy in patients with non-conventional belief systems. Recognize that patients' perceptions of benefit may go beyond direct medical care considerations, and may involve alternative belief systems and nature of reality (i.e. metaphysics).

Additionally, there is a need to consider factors beyond patient control such as age, race, gender, and socioeconomic status that may predispose patients to worse outcomes. One assessment of the final plan for resolving ethical issues is the so-called publicity test, which asks if an individual would make the same decision if the decision were open to the public. Implement

The relatively new field of implementation science is a recognition that poorly implemented plans may not yield the expected benefits to patients. Implementing a plan in a manner that optimizes patient, caregiver, institutional, and societal considerations is as important for the ethical aspects as well as the other components of the patient plan. Recognize that some acts that may be thought of as morally wrong by a patient or caregiver does not necessarily mean there are or should be hospital or governmental policies or laws prohibiting it.

Follow-Up: Monitor and Evaluate

Similar to other parts of the patient care plan, there is a need for ongoing monitoring and evaluation of decisions involving ethics. If the plan does not have the intended results, the plan may need modification or change to an alternative plan.

\section{CONCLUSION}

Whether recognized or not, pharmacists are frequently involved in ethical decision-making in the patient care setting and recognition of the importance of this issue is apparent in current ACPE accreditation standards. Although current ACPE accreditation standards (ie, Standards 2016) only mention the word "ethics" under Interprofessional Team Dynamics, Introductory Pharmacy Practice Experiences (IPPE), and in Appendix 1 (listing the required elements of the didactic curriculum) under the social/administrative/behavioral Sciences content area, an accompanying Guidance for Standards document provides additional details concerning ethics instruction. In particular, an appendix in the guidance document lists a number of expected competencies related to ethical, professional, and legal behaviors. However, regardless of ACPE requirements students in colleges of pharmacy often think of ethics as a subject associated with professional pledges or oaths at specific time points in their education rather than a subject of importance for the entire PPCP. Part of the reason for this misperception is the lack of consistency in the quantity, content, and delivery method of ethics instruction in colleges of pharmacy. These are problems beyond the scope of ACPE accreditation standards. As described in this commentary, the five basic steps of the PPCP are useful as a template for describing general ethical considerations of importance in the decision-making process, recognizing that no single approach is sufficient for all patient-care situations. There is expertise within the Academy capable of providing further practical guidance concerning the incorporation of ethics instruction of colleges of pharmacy. For example, the Health Care Ethics SIG of the American Association of Colleges of Pharmacy (AACP) has a number of individuals with education and training in ethics who can serve as content and delivery experts. AACP should also contemplate the creation of a task force to examine and provide colleges of pharmacy with guidance on issues such as the essential components of ethics instruction in the didactic curriculum. 


\section{REFERENCES}

1. Joint Commission of Pharmacy Practitioners. Pharmacists' Patient Care Process. May 29, 2014. Available at: https://jcpp.net/wp-content/uploads/2016/03/PatientCareProcess-with-supporting-organizations.pdf. Accessed January 13, 2021.

2. Accreditation Council for Pharmacy Education. PharmD Program Accreditation: ACPE Standards 2016. Accreditation standards and key elements for the professional program in pharmacy leading to the doctor of pharmacy degree. Chicago, Illinois. 2015.

3. APhA. Code of Ethics. https://www.pharmacist.com/code-ethics?is_sso_called=1. Accessed January 13, 2021.

4. AACP. Oath of a Pharmacist. https://www.aacp.org/search/content?keys=oath+of+a+pharmacist. Accessed January 13, 2021.

5. AACP. Pledge of Professionalism. https://www.aacp.org/search/content?keys=pledge+of+professionalism. Accessed January 14, 2021.

6. Brown University. A Framework for Making Ethical Decisions. https://www.brown.edu/academics/science-andtechnology-studies/framework-making-ethical-decisions. Accessed January 13, 2021.

7. Buerki RA, Vottero LD. Pharmacy Ethics: A Foundation for Professional Practice. American Pharmacists Association, Washington, DC; 2013.

8. Beauchamp TL, Childress JF. Principles of Biomedical Ethics, $8^{\text {th }}$ ed. Oxford University Press. New York, NY; 2019.

9. Markkula Center for Applied Ethics at Santa Clara University. A Framework for Ethical Decision Making. https://www.scu.edu/ethics/ethics-resources/ethical-decision-making/a-framework-for-ethical-decision-making. Accessed January 14, 2021.

10. van Oudenhoven JP, de Raad B, Timmerman ME, et al. Are virtues national, supranational, or universal? Springerplus. 2014;3:223. doi: 10.1186/2193-1801-3-223

11. Haidt J. The new synthesis in moral psychology. Science. 2007;316(5827):998-1002. doi: $10.1126 /$ science. 1137651

12. Office of the Secretary, Department of Health, Education, and Welfare. The Belmont Report. https://www.hhs.gov/ohrp/regulations-and-policy/belmont-report/read-the-belmont-report/index.html. Accessed January 28, 2021. 
Figure 1. Ethics - Theories and Approaches

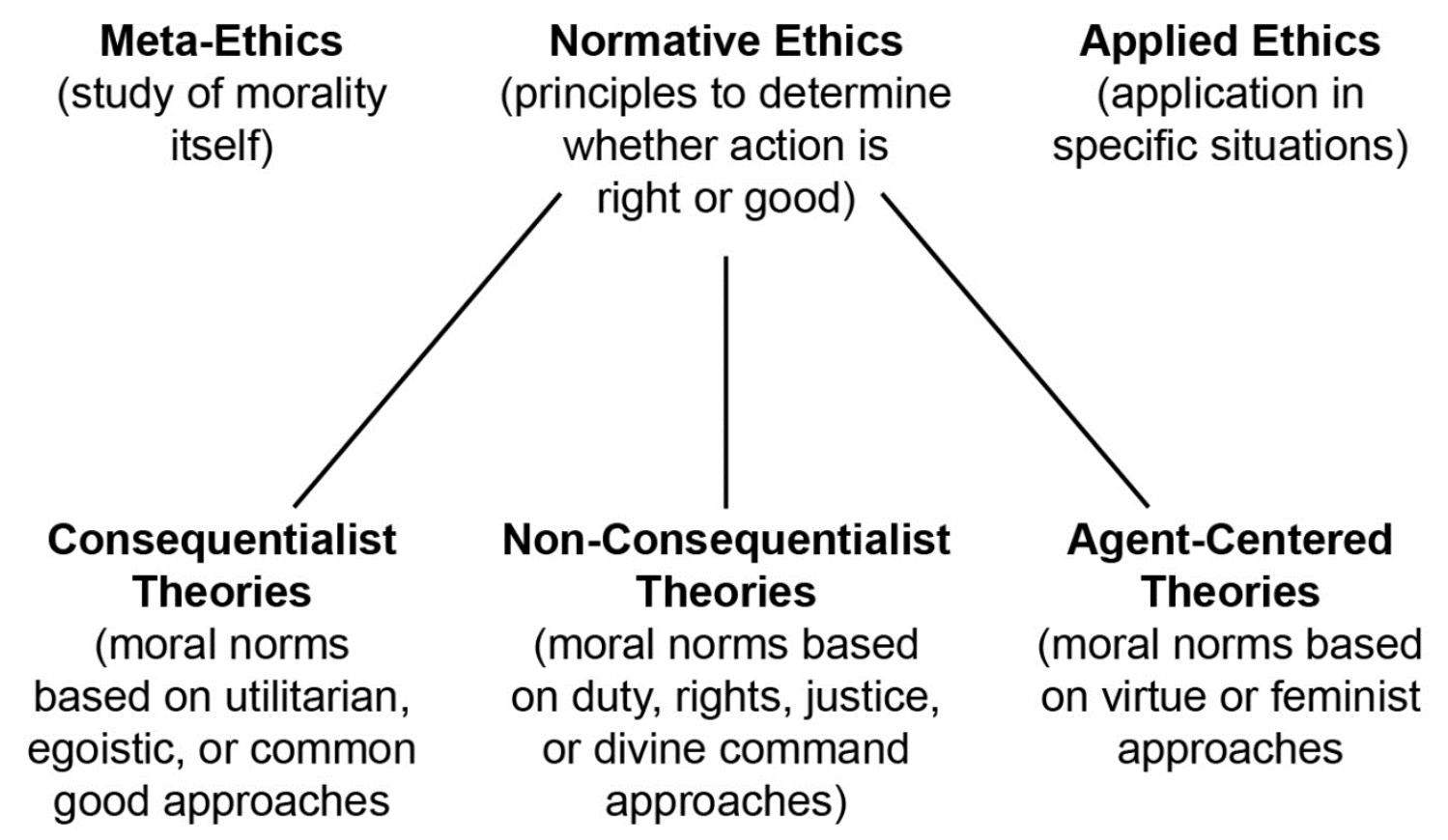




\begin{tabular}{|c|c|c|}
\hline Action & Description & Strategies Adopted \\
\hline Collect & $\begin{array}{l}\text { The pharmacist collects } \\
\text { information about patient } \\
\text { preferences and beliefs that may } \\
\text { affect ethical decision-making. }\end{array}$ & $\begin{array}{l}\text { Collect: } \\
\text { - Individuals such as family members potentially } \\
\text { involved in the decision-making process on } \\
\text { behalf of the patient. } \\
\text { - Patient preferences and beliefs with any } \\
\text { associated documentation such as an advanced } \\
\text { directive. } \\
\text { - Potential ethical issues. }\end{array}$ \\
\hline Assess & $\begin{array}{l}\text { The pharmacist assesses the } \\
\text { information collected and analyzes } \\
\text { the potential ethical implications of } \\
\text { the patient's therapy in the context } \\
\text { of the patient's preferences and } \\
\text { beliefs in order to identify and } \\
\text { prioritize problems and achieve } \\
\text { optimal care. }\end{array}$ & $\begin{array}{l}\text { Assess: } \\
\text { - Ethical alternatives if ethical issues identified. } \\
\text { - Patient perspective with respect for autonomy by } \\
\text { generally deferring to the patient (or surrogate, if } \\
\text { patient does not have requisite decision-making } \\
\text { capacity) decisions regarding their care. } \\
\text { - Caregiver and institutional perspectives. } \\
\text { - Societal perspective considering all individuals' } \\
\text { rights, treat everyone fairly, and optimize care } \\
\text { for society as a whole. }\end{array}$ \\
\hline Plan & $\begin{array}{l}\text { The pharmacist develops an } \\
\text { individualized patient-centered } \\
\text { care plan, in collaboration with } \\
\text { other health care professionals and } \\
\text { the patient or caregiver that is } \\
\text { evidence-based, cost-effective, and } \\
\text { includes consideration of possible } \\
\text { ethical implications. }\end{array}$ & $\begin{array}{l}\text { The plan: } \\
\text { - Includes optimal ethical approach with } \\
\text { justification for approach. } \\
\text { - Produces optimal care for the patient with respect } \\
\text { for autonomy while also taking into account } \\
\text { other caregiver, institutional, and societal } \\
\text { perspectives. } \\
\text { - Includes follow-up assessments to evaluate } \\
\text { factors with ethical implications that might } \\
\text { necessitate plan modification. }\end{array}$ \\
\hline Implement & $\begin{array}{l}\text { The pharmacist implements the } \\
\text { care plan in collaboration with } \\
\text { other health care professionals and } \\
\text { the patient or caregiver. }\end{array}$ & $\begin{array}{l}\text { The pharmacist: } \\
\text { - Implements the plan in a manner that optimizes } \\
\text { patient, caregiver, institutional, and societal } \\
\text { ethical considerations. }\end{array}$ \\
\hline $\begin{array}{l}\text { Follow-Up: } \\
\text { Monitor and } \\
\text { Evaluate }\end{array}$ & $\begin{array}{l}\text { The pharmacist monitors and } \\
\text { evaluates the effectiveness of the } \\
\text { care plan and modifies the plan in } \\
\text { collaboration with other health care } \\
\text { professionals and the patient or } \\
\text { caregiver as needed. }\end{array}$ & $\begin{array}{l}\text { Monitor and Evaluate: } \\
\text { Ethical considerations including unanticipated } \\
\text { consequences that arise in conjunction with plan } \\
\text { implementation that may require a change in } \\
\text { approach. }\end{array}$ \\
\hline
\end{tabular}

